\title{
Silver-coated gold nanorods as a promising antimicrobial agent in the treatment of cancer-related infections
}

This article was published in the following Dove Press journal: International Journal of Nanomedicine

\author{
Junyan Zhang' \\ Mian Wang' \\ Thomas J Webster ${ }^{1,2}$ \\ 'Department of Chemical Engineering, \\ Northeastern University, Boston, \\ MA, USA; ${ }^{2}$ Wenzhou Institute \\ of Biomaterials and Engineering, \\ Wenzhou Medical University, \\ Wenzhou, Zhejiang, China
}

\begin{abstract}
Background: Many cancer patients suffer from cancer-related life-threatening infections due to immune system damage. Therefore, researchers are continuously looking for new options to treat cancer-related infections. As nanotechnology has gained tremendous interest over the past several decades, silver nanoparticles have been investigated as an effective antimicrobial agent. Here, silver-coated gold nanorods were synthesized to share similar optical properties as gold nanoparticles for cancer diagnosis and treatment, with an added advantage of antibacterial properties.

Results: Their dose-dependent antimicrobial properties were demonstrated on both Gramnegative and Gram-positive bacteria species. These nanorods were found to be highly efficient in killing bacteria and suppressing biofilm formation.

Conclusion: Collectively, such results suggest that silver-coated gold nanorods should be further investigated as a novel material, which can both decrease cancer cell functions and reduce the risk of infection for cancer patients.
\end{abstract}

Keywords: nanotechnology, bacteria, cancer cells, infrared excitation

\section{Background}

Cancer is the second most deadly disease in the USA and can easily lead to life-threatening infections in patients due to their weakened immune systems. ${ }^{1-5}$ The immune system of cancer patients can be damaged either directly by certain types of cancer, like lymphoma, or by cancer treatments, which include any type of major surgery, radiation therapy, immunotherapy, chemotherapy, and the removal of immune system organs such as the spleen. ${ }^{4,6,7}$ Moreover, the increasing prevalence of antibiotic-resistant pathogens due to antibiotic overuse has posed an even greater challenge in treating cancer patients. ${ }^{8}$ The antibiotic-resistant bacterial strains, or the so-called "super bugs", have been reported to evolve dramatically over the years and become resistant to even the most effective antibiotics available. ${ }^{9}$ Therefore, it is of great importance and necessity to research alternative approaches to combat infections, especially those happening to cancer patients.

Silver has been applied to treat infections even long before the discovery of microbes, but lost its status during the 1930 s to antibiotics. ${ }^{10-12}$ In recent years, silver, in the form of nanoparticles, has made a remarkable comeback as a promising antimicrobial agent after recent advances in nanotechnology have provided innovative solutions for many applications. ${ }^{13,14}$ Silver nanoparticles (AgNPs) have been proven to be an efficient antimicrobial agent, even to multidrug-resistant bacteria strains, due to their extremely large surface-area-to-volume ratio, which provides a better chance for contact with bacteria and generation of ROS. ${ }^{14-16}$ Hence, AgNPs have been widely 
researched for diverse medical applications including silverbased dressings and silver-coated medical devices, among others. ${ }^{17,18}$ For example, Maneerung et al demonstrated that silver nanoparticle-impregnated bacterial cellulose (a wound dressing material) exhibited strong antimicrobial properties against both Gram-positive and Gram-negative bacteria. ${ }^{17}$ However, AgNPs have been found to cause DNA damage in mammalian cells as well as chromosomal aberrations and cell cycle arrest in a dose-dependent manner. ${ }^{19}$ Therefore, in order to employ the super antimicrobial properties of AgNPs, more studies are needed to reduce the amount of AgNPs needed, while achieving a comparable antimicrobial effect toward multiple bacteria strains.

Along this line, silver-coated gold nanoparticles of various shapes have been synthesized and investigated as a potential solution. ${ }^{20-22}$ Among them, silver-coated gold nanorods (Ag/AuNRs) have attracted much interest due to their facile synthesis and easy tenability. ${ }^{21,23}$ The core-shell structure is obtained by forming gold nanorods first using the seed-mediated growth method proposed by Nikoobakht and El-Sayed, and then depositing silver onto the surface of the nanorods. ${ }^{24,25}$ The $\mathrm{Au}-\mathrm{Ag}$ bimetallic material shares similar optical properties as those of gold nanoparticles, thus demonstrating promise in cancer detection and treatment through temperature increases after radiation, which originates from the localized surface plasmon resonance (LSPR) effect. ${ }^{26,27}$ Moreover, by modulating the aspect ratio of the core structure, or the gold nanorods in this case, the LSPR band of the bimetallic nanorods can be tuned into the near infrared region (NIR region), allowing for potential use in various biomedical applications. ${ }^{24}$ Gold nanoparticles have been investigated for their cancer cell imaging and photothermal therapy in the NIR region. ${ }^{28-31}$ NIR can be used to ablate tumor cells in vivo because such light can penetrate deeper into human tissue and blood. The Ag/AuNRs can also have high absorbance of NIR light when their LSPR band lies in the NIR region. ${ }^{24}$ Therefore, Ag/AuNRs are promising candidates for the combined therapy of cancer and cancer-related infections. However, the potential Ag/AuNRs for antimicrobial applications has not been well studied to date.

In the present in vitro study, we focused on the antimicrobial properties of $\mathrm{Ag} / \mathrm{AuNRs}$ for cancer patients. First, the aforementioned nanorods were synthesized and characterized. The synthesis process was completed under different conditions to investigate the subsequent effect of each condition on the morphology of the Ag/AuNRs. Then, the antimicrobial properties of the $\mathrm{Ag} / \mathrm{AuNRs}$ were tested on both Gram-negative and Gram-positive bacteria species.
Transmission electron microscope (TEM) images of the nanoparticle-treated and non-treated bacteria were investigated to reveal the possible working mechanisms of the Ag/AuNRs. Furthermore, fluorescence assays on Staphylococcus aureus and Staphylococcus epidermidis showed the influence of $\mathrm{Ag} / \mathrm{AuNRs}$ on bacterial growth and biofilm formation compared with control groups.

\section{Materials and methods Synthesis of Ag/AuNRs}

Gold nanorods were synthesized using the seed-mediated growth method described by Nikoobakht and El-Sayed ${ }^{25}$ and the process was carried out in the same way as in the study by Zhang et $\mathrm{al}^{32}$ until before the centrifugation step. The seed solution was prepared by adding $5 \mathrm{~mL}$ of a $0.2 \mathrm{M}$ cetyltrimethylammonium bromide (CTAB) aqueous solution to $5 \mathrm{~mL}$ of a $0.0005 \mathrm{M} \mathrm{HAuCl}_{4}$ aqueous solution, followed by adding $0.6 \mathrm{~mL}$ of ice-cooled $0.01 \mathrm{M} \mathrm{NaBH}_{4}$. The solution was stirred vigorously for 2 minutes and then kept at room temperature. The growth solution of AuNRs was prepared by adding 5 $\mathrm{mL}$ of $0.2 \mathrm{M}$ CTAB to $0.3 \mathrm{~mL}$ of a $0.004 \mathrm{M} \mathrm{AgNO}_{3}$ aqueous solution. Then, $5 \mathrm{~mL}$ of $0.001 \mathrm{M} \mathrm{HAuCl}_{4}$ was added and the solution was gently hand-shaken. Then, $70 \mu \mathrm{L}$ of $0.0788 \mathrm{M}$ ascorbic acid was added. The solution changed from dark yellow to colorless after being hand-shaken. Soon after, $12 \mu \mathrm{L}$ of the seed solution was added to the growth solution. After equilibrating at room temperature for 15 minutes, the solution was centrifuged at $11,000 \mathrm{rpm}$ for 20 minutes at $40^{\circ} \mathrm{C}$. The supernatant was taken out and the remaining pellet was dispersed in $3 \mathrm{~mL}$ of deionized (DI) water or CTAB.

The deposition of silver on top of the above synthesized gold nanorods was achieved by modifying the method proposed by Park and Vaia. ${ }^{24}$ Briefly, after the pellet was dispersed in $3 \mathrm{~mL}$ of DI water or CTAB, $4 \mu \mathrm{L}$ of $1 \mathrm{M}$ $\mathrm{NaOH}$ was added to the gold nanorod solution in order to adjust the $\mathrm{pH}$. Then, $1 \mathrm{~mL}$ of the $0.001 \mathrm{M} \mathrm{HAuCl}_{4}$ aqueous solution, $0.75 \mathrm{~mL}$ of the $0.004 \mathrm{M} \mathrm{AgNO}_{3}$ aqueous solution, and $25.38 \mu \mathrm{L}$ of $0.0788 \mathrm{M}$ ascorbic acid were added into the solution in this order. The solution was gently handshaken and kept at $37^{\circ} \mathrm{C}$ for 20 minutes to allow for silver deposition. The solution was then centrifuged at $11,000 \mathrm{rpm}$ for 20 minutes at $40^{\circ} \mathrm{C}$. The obtained pellet was dispersed in PBS and the $\mathrm{pH}$ was adjusted to 7.4 before use. The $\mathrm{Ag} / \mathrm{AuNRs}$ were diluted into a series of concentrations for bacteria and cell experiments: 0, 50, 75, 100, 125 and $150 \mu \mathrm{g} / \mathrm{mL}$ for the growth curves of Gram-negative bacteria; and $0,10,20,30,40$ and $50 \mu \mathrm{g} / \mathrm{mL}$ for the growth curves of Gram-positive bacteria. 


\section{Characterization of $\mathrm{Ag} / \mathrm{AuNRs}$}

A JEOL JEM-101 TEM was used to characterize the average size and shape of the nanoparticles. Size distributions of the nanorods were obtained by measuring TEM images from at least 100 nanorods using ImageJ. Nonlinear Gaussian distribution curves were used to fit the size distributions and to get the average length, width, and aspect ratios of the nanorods. Ultraviolet-visible (UV-Vis) spectroscopy (SpectraMax M3, Molecular Devices) was used to test the difference in the absorption spectra of gold nanorods and $\mathrm{Ag} /$ AuNRs. Scanning electron microscopy with energy dispersive X-ray (SEM/EDX) spectroscopy was used for elemental analysis of the $\mathrm{Ag} / \mathrm{AuNR}$ to prove the successful deposition of silver.

\section{Bacterial growth curve assays}

Two Gram-negative bacteria, Pseudomonas aeruginosa (ATCC 27853) and Escherichia coli (ATCC 25922), and two Gram-positive bacteria, S. aureus (ATCC 12600) and S. epidermidis (ATCC 35984), were used to test the antimicrobial properties of the coated nanorods. All the bacterial species were inoculated into $5 \mathrm{~mL}$ of $30 \mathrm{~g} / \mathrm{L}$ Tryptic soy broth (TSB) from their single-isolated bacterial colonies. The bacteria were cultured overnight in a shaking incubator at $37^{\circ} \mathrm{C}$ and then diluted ten times in the media. The optical density (OD) of the bacteria solutions was obtained through UV-Vis spectroscopy using a microplate reader at $600 \mathrm{~nm}$. Bacteria solutions were then diluted to a final density of $10^{6} \mathrm{cell} / \mathrm{s} / \mathrm{mL}$. The diluted bacteria solutions were added into a 96-well plate, with three replicates for each condition. A series of diluted nanoparticle solutions were added into the bacteria solution with $0.1 \mathrm{~mL}$ to each well: $0,50,75,100,125$, and $150 \mu \mathrm{g} / \mathrm{mL}$ for Gram-negative bacteria, and $0,10,20,30$, 40 , and $50 \mu \mathrm{g} / \mathrm{mL}$ for Gram-positive bacteria, making the final concentrations: $0,25,37.5,50,62.5$, and $75 \mu \mathrm{g} / \mathrm{mL}$ for Gram-negative bacteria, and $0,5,10,15,20$, and $25 \mu \mathrm{g} / \mathrm{mL}$ for Gram-positive bacteria. The plate was well mixed for 5 minutes and then placed inside a spectrophotometer for incubation. The OD was measured at $600 \mathrm{~nm}$ every 2 minutes for about 20 hours to get the bacterial growth curves.

\section{Bacterial TEM}

Gram-positive bacteria species, S. aureus, were treated with $\mathrm{Ag} /$ AuNRs for TEM imaging in order to have a closer observation of the cell membranes. Briefly, $100 \mu \mathrm{L}$ of $10^{7}$ cells $/ \mathrm{mL}$ of $S$. aureus was treated with TSB supplemented with $\mathrm{Ag} / \mathrm{AuNRs}$ at a final concentration of $15 \mu \mathrm{g} / \mathrm{mL}$ for 24 hours at $37^{\circ} \mathrm{C}$. The bacteria were centrifuged and then fixed with
$2.5 \%$ glutaraldehyde in a $0.1 \mathrm{M}$ sodium cacodylate buffer overnight at $4^{\circ} \mathrm{C}$. The bacteria pellets were rinsed three times with sodium cacodylate buffer and then post-fixed with $1 \%$ osmium tetroxide for 2 hours and dehydrated with gradient ethanol solutions $(30 \%, 50 \%, 70 \%, 85 \%, 90 \%$, and $100 \%)$. Samples were infiltrated with squetol resin. The resins were polymerized at $60^{\circ} \mathrm{C}$ for 24 hours and thin-sectioned using an ultra-microtome (Reichert-Jung Ultracut E, Reichert Technologies, Buffalo, NY, USA). The sectioned samples were mounted on 200-hex mesh copper-coated carbon grids for imaging.

\section{Fluorescence assay}

Two Gram-positive bacteria species, S. aureus and S. epidermidis, were used for the biofilm fluorescence assay. Biofilms were allowed to form on glass coverslips submerged with $1 \mathrm{~mL}$ of TSB in a 24 -well plate at $37^{\circ} \mathrm{C}$ for 24 hours. Then, the supernatant containing non-adhered cells was removed and the coverslips were washed with sterile PBS. Existing biofilms were incubated for another 24 hours with TSB supplemented with different concentrations of $\mathrm{Ag} / \mathrm{AuNRs}$, making the final concentrations: 0, 15 and $25 \mu \mathrm{g} / \mathrm{mL}$. Biofilms were fixed using a $4 \%$ paraformaldehyde solution for 30 minutes at room temperature and then were washed three times with PBS. After that, 5-(4, 6-dichlorotriazinyl) aminofluorescein was added into the wells and the samples were allowed to incubate with shaking for 2 hours at room temperature. The coverslips were washed three times in PBS and inverted onto a cover glass. Images were acquired using a Zeiss Axio Observer Inverted microscope (Carl Zeiss Meditec AG, Jena, Germany).

\section{Statistical analysis}

All experiments were performed in triplicate $(\mathrm{N}=3)$ with three replicates each. Data are presented as the mean value with SD. Statistical differences were determined by Student's $t$-tests. The critical $P$-value was set at 0.05 ; a probability value of $P<0.05$ was considered to be statistically significant.

\section{Results}

\section{Characterization of $\mathrm{Ag} / \mathrm{AuNRs}$}

The as-synthesized Ag/AuNRs were characterized using a TEM, EDX and UV-Vis spectroscopy. The results are shown in Figure 1.

Figure 1 (A and B) are the TEM images of the synthesized $\mathrm{Ag} / \mathrm{AuNRs}$ under different conditions. For (A), the gold nanorods were first synthesized and then redispersed in DI water before the deposition of silver; while for (B), the gold 

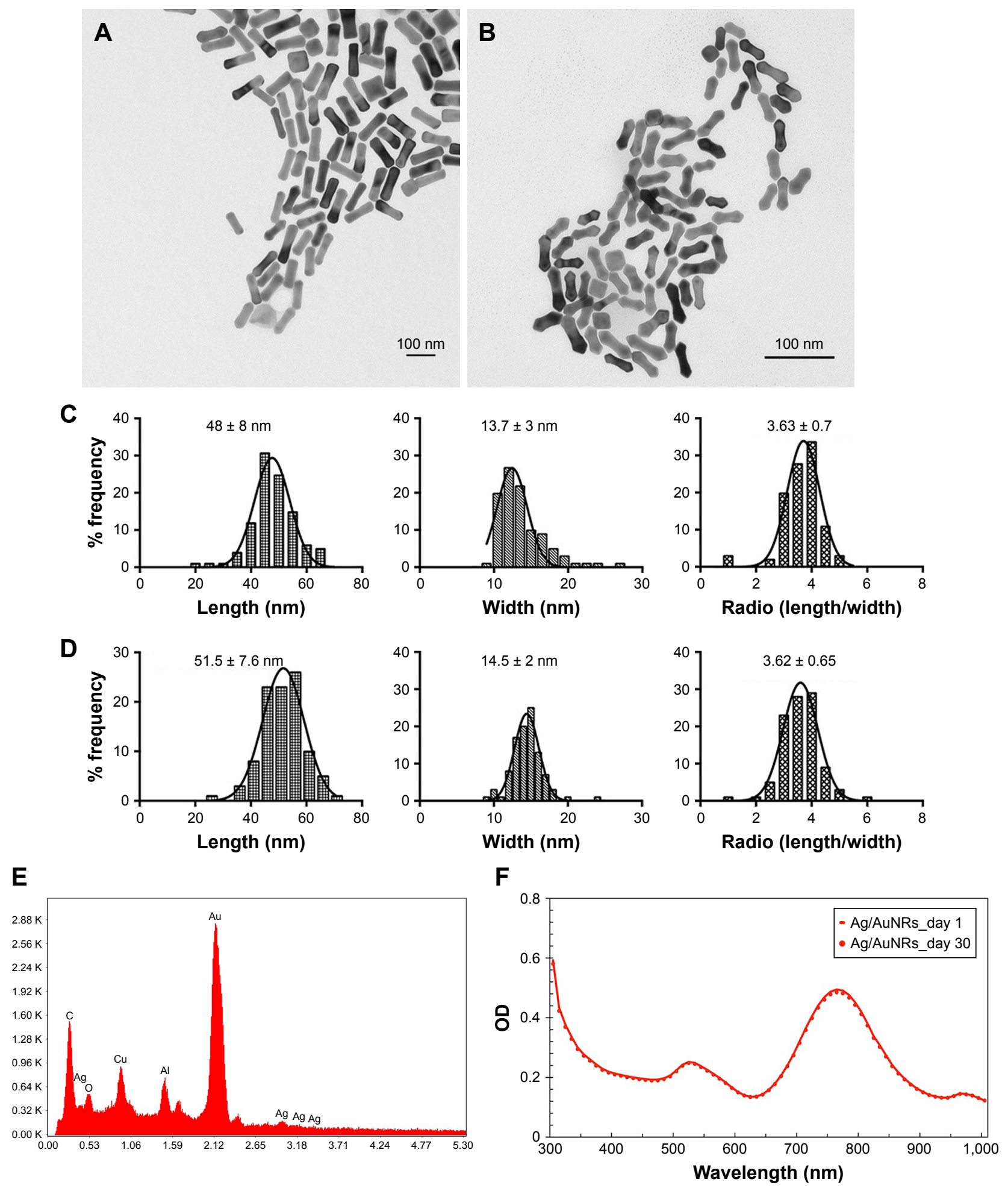

Figure I Characterization of the synthesized Ag/AuNRs. (A) and (B) transmission electron microscope images of Ag/AuNRs. (C) and (D) statistical analysis of the length, width and aspect ratio of the synthesized Ag/AuNRs in (A) and (B), respectively. A Gaussian distribution was fitted for each plot. (E) EDX analysis of Ag/AuNRs. (F) UV-Vis spectra of Ag/AuNRs on days I and 30, stored at room temperature.

Abbreviation: EDX, energy dispersive X-ray; UV-Vis, ultraviolet-visible.

nanorods were redispersed in CTAB. The morphology of $\mathrm{Ag} / \mathrm{AuNRs}$ for (A) was regular-shaped rods with a rectangle side view, while that for (B) were a more dumbbell-like shape with two sharp tips on both ends.
The statistical analysis of the size distribution of the $\mathrm{Ag} / \mathrm{AuNRs}$ as shown in Figure 1(A and B) was carried out through measuring the length, width, and aspect ratio (length/width) of 100 separate nanorods from the obtained 
TEM images (Figure 1C and D). The "width" of the nanorods in Figure 1B was represented by the narrowest width in the middle of the dumbbell-like nanorods. The size distribution of the original gold nanorods before the deposition of silver can be found in the study by Zhang et al, ${ }^{32}$ which was conducted under exactly the same conditions. Compared with the previous results, both the length and the width increased after silver deposition. However, the aspect ratio decreased from about 4.5 to 3.6 due to a disproportional deposition along the length and width directions. Compared with the Ag/AuNRs that were redispersed in DI water (Figure 1), those that were redispersed in CTAB had a slightly larger average length and width, suggesting that $\mathrm{CTAB}$ enhanced the deposition of silver on top of the original surface. Since the dumbbell-like shape of $\mathrm{Ag} / \mathrm{AuNRs}$ in Figure 1 had two sharp tips on both ends, this suggests that they can be used for enhancing the photothermal therapy efficacy in a future study. Elongated or sharp nanoparticles are more efficient at increasing temperatures, allowing the entire nanoparticle to be involved in heating. ${ }^{33-35}$ The following studies focused on the dumbbell-like Ag/AuNRs.

EDX was carried out on the Ag/AuNRs for elementary analysis (Figure 1E). Both elements, gold and silver, were found in the components of the nanorods. From the literature, silver was not observed in the gold nanorods synthesized through the same seed-mediated method. ${ }^{24}$ Therefore, silver was not present until the final deposition step, demonstrating the successful deposition of silver onto the gold nanorods. Other elements shown in the analytical result include $\mathrm{Cu}$ from the copper TEM grid, $\mathrm{Al}$ from the SEM holder that was made of aluminum, and $\mathrm{C}$ from the carbon tape that was used to fix the TEM grid onto the SEM holder.

Moreover, there was not much difference in the absorbance spectra of the $\mathrm{Ag} / \mathrm{AuNRs}$ right after synthesis (Ag/ AuNRs_day 1) and those stored for 30 days at room temperature (Ag/AuNRs_day 30) (Figure 1), suggesting that the synthesized Ag/AuNRs could be stored at room temperature without much change for at least 30 days. In spectra for both storage conditions, the longitudinal and transverse surface plasmon absorption peaks existed. The transverse absorption peak was relatively fixed while the longitudinal one could be tuned into different wavelengths. In this study, the longitudinal peak located at around 740-760 nm was slightly different between batches. However, although a difference was observed, every longitudinal peak was still located in the NIR region for each batch, showing much promise for future research on the photothermal therapy of these nanoparticles.

\section{Inhibition of bacterial growth}

The antimicrobial properties of the synthesized Ag/AuNRs at different concentrations were tested on both Gram-negative bacteria species ( $P$. aeruginosa and E. coli) and Grampositive bacteria species (S. aureus and S. epidermidis), and the growth curves of the bacterial species were examined by measuring the $\mathrm{OD}$ at $600 \mathrm{~nm}\left(\mathrm{OD}_{600}\right)$ for at least 20 hours after adding the nanoparticles. OD was then converted to bacteria cell number through the estimation: $1 \times 10^{9}$ cells $/ \mathrm{mL}$ at $\mathrm{OD}_{600}=1$ and the growth curves were plotted as shown in Figure 2.

The response of bacteria toward the Ag/AuNRs was dose-dependent, and higher concentrations could both delay the growth and suppress the final bacteria concentration reached. For Gram-negative bacteria, the added nanorods started to influence the bacteria growth at a concentration of $37.5 \mu \mathrm{g} / \mathrm{mL}$ and obvious suppression was found at a concentration of $62.5 \mu \mathrm{g} / \mathrm{mL}$. When the concentration was $75 \mu \mathrm{g} / \mathrm{mL}$, the growth was completely suppressed for at least 20 hours. The Ag/AuNRs performed better on Gram-positive bacteria species, with a total suppression for at least 20 hours at a concentration as low as $25 \mu \mathrm{g} / \mathrm{mL}$. This is due to the different structures between Gram-negative and Gram-positive bacteria species. The former ones have an outer membrane that provides extra protection toward the Ag/AuNRs.

TEM was used to evaluate the morphology of the $S$. aureus after being treated with $15 \mu \mathrm{g} / \mathrm{mL}$ of $\mathrm{Ag} / \mathrm{AuNRs}$ for 24 hours (Figure 3). From both Figure 3(A and B), bacterial membranes showed major damage and there were "pits" formed on the cell walls, leading to leakage of the intracellular substances into the surround environment. Ag/AuNRs accumulated and coagulated near the damaged bacteria. However, there is no direct evidence of the nanoparticles penetrating the cell membrane and entering the cells.

The fluorescence assay was carried out on Grampositive bacteria species, S. aureus (Figure 4(A)-(C)) and S. epidermidis (Figure 4(D)-(F)), as described in the Materials and methods section. There were three groups treated with different concentrations of Ag/AuNRs, 0 ((A) and (D)), $15 \mu \mathrm{g} / \mathrm{mL}$ ((B) and (E)), and $25 \mu \mathrm{g} / \mathrm{mL}$ ((C) and $(\mathrm{F}))$. In Figure 4A and D, a large amount of bacteria and complex biofilm matrices could be observed, indicating the healthy status of the two bacterial species. In (B) and (E), although there were still a lot of bacteria, the formation of biofilms was greatly suppressed. While at the highest concentration, $25 \mu \mathrm{g} / \mathrm{mL}$, most of the bacterial cells were killed compared with the control group, and no formation of biofilm was found in the fluorescence images. Therefore, the $\mathrm{Ag} / \mathrm{AuNRs}$ were efficient in destroying the existing bacteria, 
A

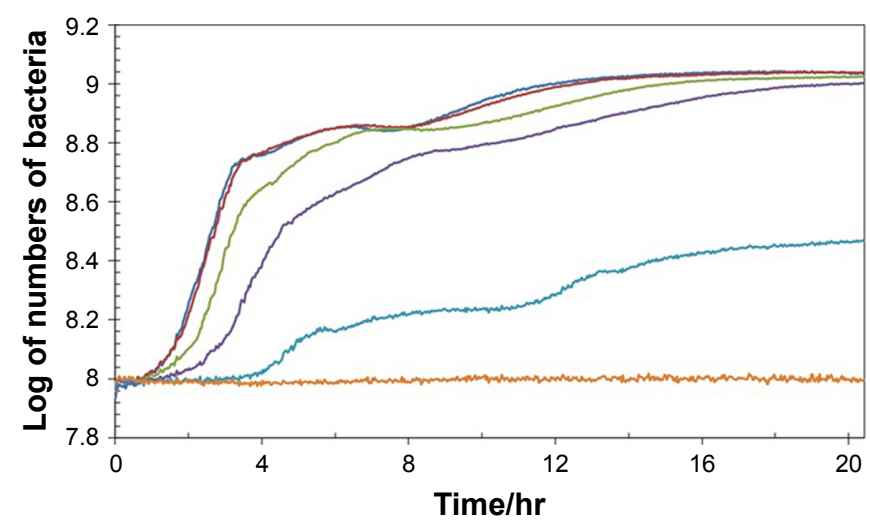

B

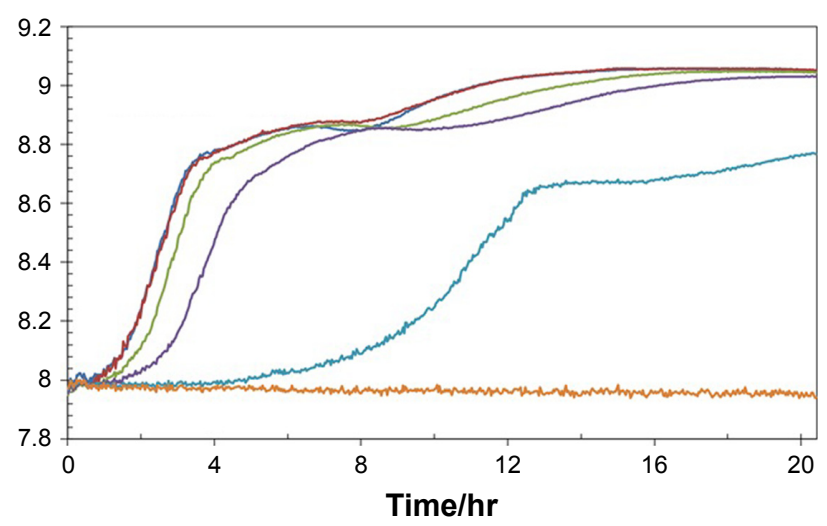

\section{- Control $-25 \mu \mathrm{g} / \mathrm{mL} \quad-37.5 \mu \mathrm{g} / \mathrm{mL} \quad-50 \mu \mathrm{g} / \mathrm{mL} \quad-62.5 \mu \mathrm{g} / \mathrm{mL} \quad-75 \mu \mathrm{g} / \mathrm{mL}$}

c

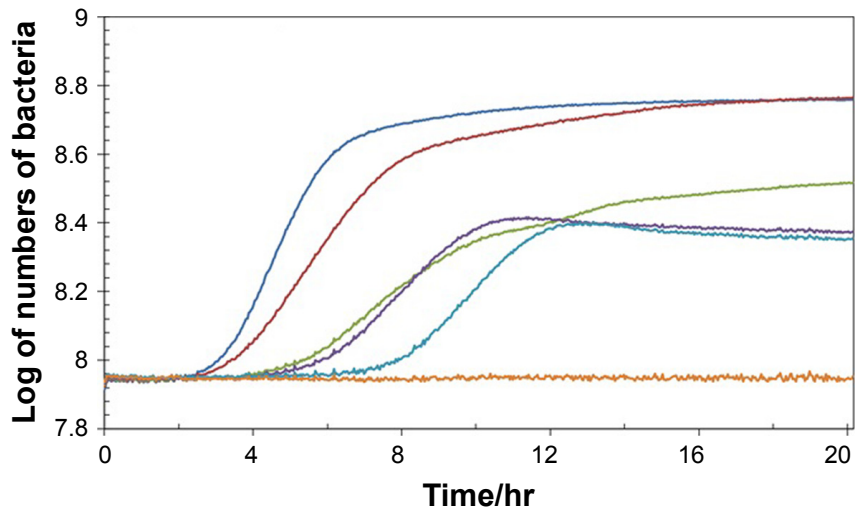

D

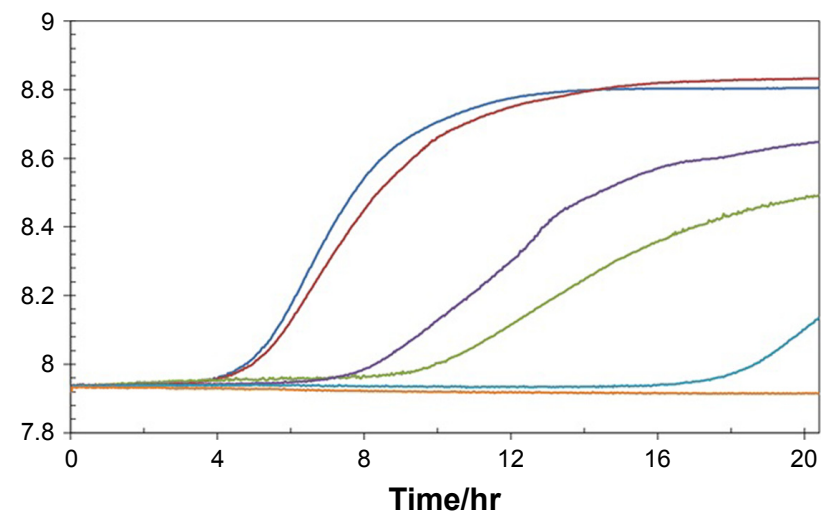

- Control $-5 \mu \mathrm{g} / \mathrm{mL} \quad-10 \mu \mathrm{g} / \mathrm{mL} \quad-15 \mu \mathrm{g} / \mathrm{mL} \quad-20 \mu \mathrm{g} / \mathrm{mL} \quad-25 \mu \mathrm{g} / \mathrm{mL}$

Figure 2 Bacteria growth curves for Gram-negative bacteria strains: (A) Pseudomonas aeruginosa and (B) Escherichia coli and Gram-positive bacteria strains, (C) Staphylococcus aureus, and (D) Staphylococcus epidermidis under different concentrations of Ag/AuNRs.
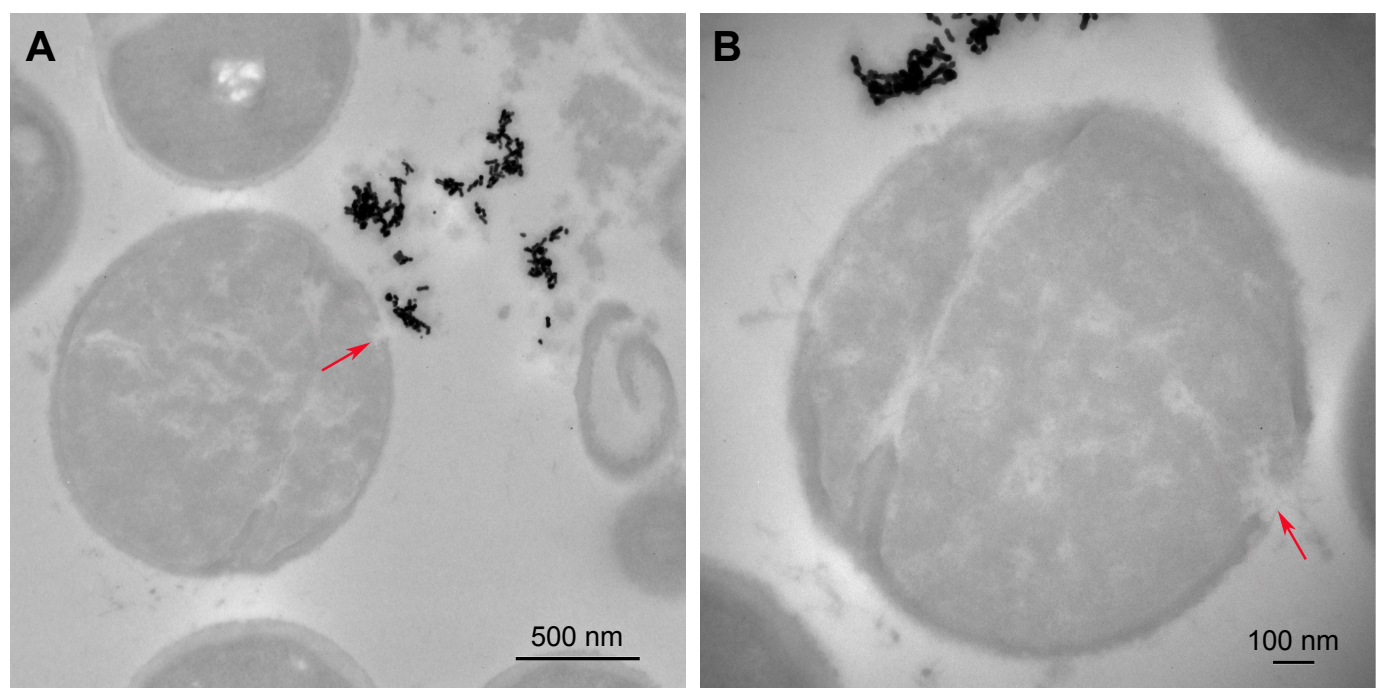

Figure 3 TEM images of Staphylococcus aureus after treated with $15 \mu \mathrm{g} / \mathrm{mL}$ of Ag/AuNRs for 24 hours. Arrows indicate where "Pits" were formed on the cell membrane. Note: (A) Low magnification, (B) high magnification.

Abbreviation: TEM, transmission electron microscope. 

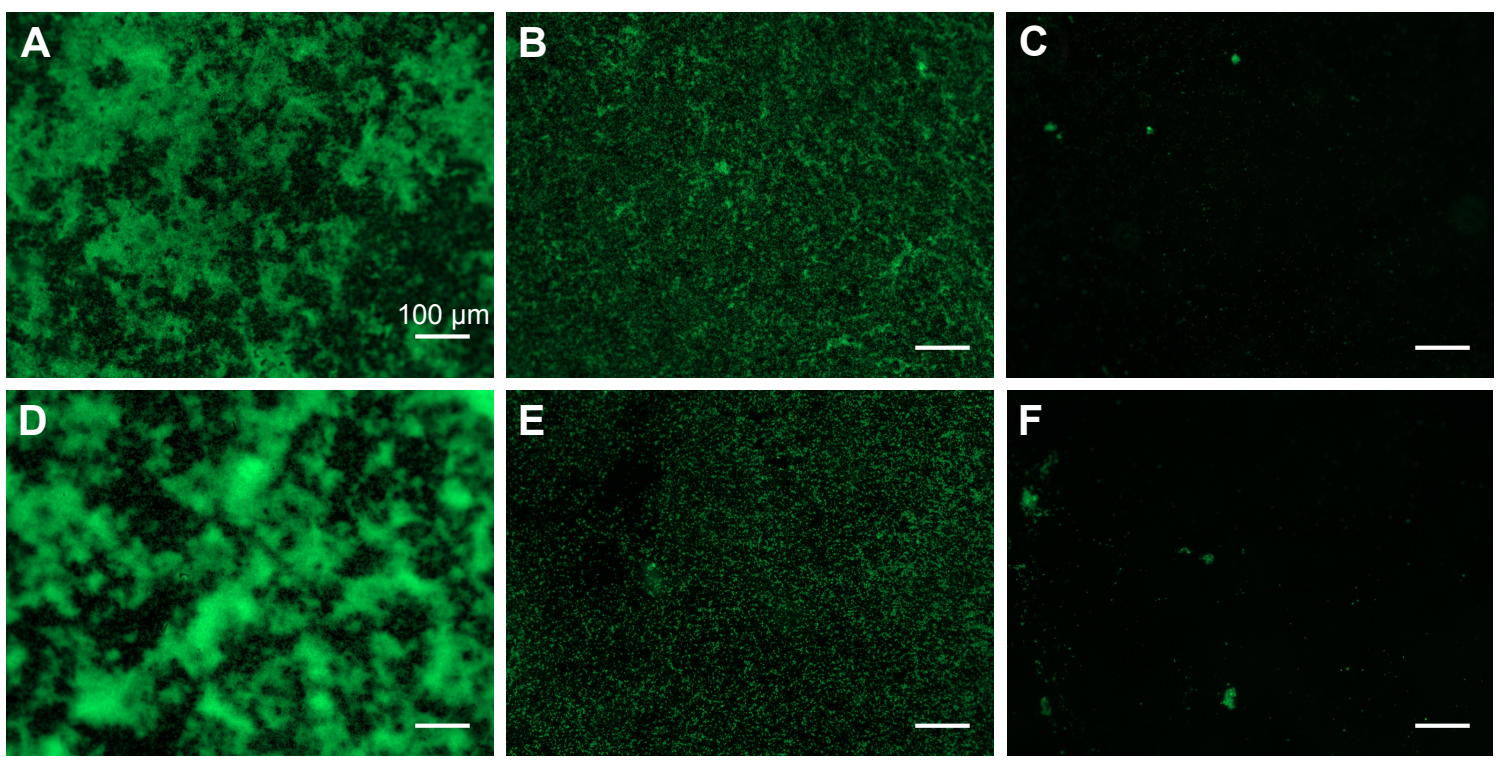

Figure 4 Fluorescence imaging of Staphylococcus aureus (A-C) and Staphylococcus epidermidis (D-F) after treating with Ag/AuNRs for 24 hours at a concentration of 0 (A, D), 15 (B, E) and 25 (C, F) $\mu \mathrm{g} / \mathrm{mL}$, respectively.

suppressing bacteria proliferation, and biofilm formation. This was accomplished without using antibiotics and, thus, this approach does not contribute to the growing clinical problem of antibiotic-resistant bacteria.

\section{Discussion}

The mechanism of the antimicrobial properties of AgNPs has been studied. ${ }^{15,36,37}$ AgNPs exhibit efficient antimicrobial properties compared with other salts due to their large surface area, providing better contact with cells, and increased generation of ROS due to their larger surface areas. ${ }^{14}$ It has been reported that AgNPs can damage the cell membrane and form "pits" in the cell walls, causing leakage of intracellular substances. ${ }^{15}$ Moreover, AgNPs can penetrate the cell membrane and interact with sulfur-containing proteins in the membrane and inside the cells and also the phosphoruscontaining compounds, like DNA, in the cells. ${ }^{36}$ However, in our study, there was no direct evidence of the nanoparticles entering the bacterial cells from the TEM images. This is because the antimicrobial properties of nanoparticles are size-dependent and nanoparticles smaller than $10 \mathrm{~nm}$ have the ability of penetrating the cell membranes. ${ }^{14,36} \mathrm{The} \mathrm{Ag} /$ AuNRs in our study had an average length of about $50 \mathrm{~nm}$ and average width of about $15 \mathrm{~nm}$, which might be too large to penetrate the bacterial membrane. The main antibacterial mechanism observed in this study was an increased formation of "pits" on the bacterial membrane, which was caused by the interaction between silver nanoparticles and constituents of the bacterial membrane, leading to the leakage of intercellular contents and the release of silver ions into the cell, which also interacted with bacteria to cause death. ${ }^{15}$

The bimetallic nanoparticles chosen for our study aimed to reduce the amount of AgNPs needed to achieve sufficient antimicrobial efficacy. This is because AgNPs have been found to be equally toxic to mammalian cells, which greatly limits their potential applications in the biomedical area. ${ }^{38}$ It has been reported that for rod-shaped AgNPs, a total of $50-100 \mu \mathrm{g}$ of silver is needed in order to possess antimicrobial efficacy. ${ }^{14}$ However, it was demonstrated in this study that a much lower concentration of silver is needed in order to suppress the proliferation of Gram-positive bacteria species. The efficient concentration of Ag/AuNRs was $25 \mu \mathrm{g} / \mathrm{mL}$ here, including both $\mathrm{Ag}$ and $\mathrm{Au}$. Notably, since silver was only coated onto the gold nanorods, it accounts for less than $1 / 10$ of the total nanoparticle composition, which was also confirmed by inductively coupled plasma mass spectrometry (ICP-MS) tests when measuring the concentration of the nanorods. Therefore, through the silver coating, much less silver was needed to achieve the same antimicrobial efficacy as those demonstrated in previous studies with pure AgNPs.

In this study, two different shapes of Ag/AuNRs were synthesized, the normal rod shape and the dumbbell-like shape with two sharp tips at both ends. The latter was used for further investigating bacterial and cell interactions because they had the potential to be employed for the photothermal 
therapy on cancer cells in future research. It has been demonstrated that elongated or sharp nanoparticles are more efficient at increasing temperatures than massive nanostructures because the incoming electrical field can penetrate more easily inside the thin nanostructures, allowing the entire nanoparticle to be involved in heating. ${ }^{33-35}$ The increase in temperature can promote the photothermal therapy efficacy on tumor cells. Also, by changing the aspect ratio of the core structure of the Ag/AuNRs, their plasmon band could be easily adjusted into the NIR region. NIR can be used to ablate tumor cells in vivo because such light can penetrate deeper into human tissue and blood. Therefore, the Ag/AuNRs synthesized in our study have the potential of a combined therapy of cancer and cancer-related infections, which should be further studied. In addition, this study introduces a new field where one can potentially use the same material (without drugs or antibiotics) to kill cancer cells and bacteria for which cancer patients have increased susceptibility.

\section{Conclusion}

Ag/AuNRs were synthesized under different conditions and characterized using TEM, EDX, and UV-Vis. Then, the antimicrobial properties of the synthesized nanorods were tested on both Gram-negative and Gram-positive bacteria species and their growth was suppressed with increasing nanoparticle concentrations. The suppression of Gram-positive bacteria was more notable with complete suppression of bacteria growth for more than 20 hours at a concentration as low as $25 \mu \mathrm{g} / \mathrm{mL}$ due to the structural differences between Gramnegative and Gram-positive bacteria species, the former having an outer membrane that provides extra protection. Furthermore, TEM images showed "pits" on the treated $S$. aureus membrane, leading to leakage of intercellular substances into the surrounding environment. Also, fluorescence assays were carried out on $S$. aureus and S. epidermidis, and compared with the control groups; the groups with $25 \mu \mathrm{g} /$ $\mathrm{mL}$ of $\mathrm{Ag} / \mathrm{AuNRs}$ showed much less bacteria and no formation of biofilms. Moreover, since the LSPR band of the synthesized Ag/AuNRs was located in the NIR region, these nanoparticles are promising in applications such as combined cancer therapy and cancer-related infections.

\section{Disclosure}

The authors declare that there is no conflict of interests.

\section{References}

1. American Cancer Society, Cancer Facts \& Figures 2017, Cancer Facts Fig. 2017. (2017) 1.
2. Segal BH, Almyroudis NG, Battiwalla M, et al. Prevention and early treatment of invasive fungal infection in patients with cancer and neutropenia and in stem cell transplant recipients in the era of newer broadspectrum antifungal agents and diagnostic adjuncts. Clin Infect Dis. 2007;44(3):402-409.

3. Wade JC, Schimpff SC, Newman KA, Wiernik PH. Staphylococcus epidermidis: an increasing cause of infection in patients with granulocytopenia. Ann Intern Med. 1982;97(4):503-508.

4. Bodey GP. Infection in cancer patients. A continuing association. Am J Med. 1986;81(1A):11-26.

5. Rolston KV, Bodey GP, Safdar A. Polymicrobial infection in patients with cancer: an underappreciated and underreported entity. Clin Infect Dis. 2007;45(2):228-233.

6. Janeway CA. Immunobiology: The Immune System in Health and Disease. Churchill Livingstone. Vol. 1: Current Biology Singapore; 1997.

7. Morris DH, Bullock FD. The importance of the spleen in resistance to infection. Ann Surg. 1919;70(5):513-531.

8. Levy SB, Marshall B. Antibacterial resistance worldwide: causes, challenges and responses. Nat Med. 2004;10(12 Suppl): S122p-S129p.

9. Arias CA, Murray BE. Antibiotic-resistant bugs in the 21 st century-a clinical super-challenge. $N$ Engl J Med. 2009;360(5):439-443.

10. Hill WR, Pillsbury DM. Argyria: The Pharmacology of Silver. Williams \& Wilkins Company; Baltimore. 1939.

11. Alexander JW. History of the medical use of silver. Surg Infect. 2009; 10(3):289-292.

12. Barillo DJ, Marx DE. Silver in medicine: A brief history BC 335 to present, Burns. 2014(40)Suppl 1; S3-S8.

13. Cao G. Nanostructures and Nanomaterials: Synthesis, Properties and Applications: World Scientific; 2004.

14. Rai M, Yadav A, Gade A. Silver nanoparticles as a new generation of antimicrobials. Biotechnol Adv. 2009;27(1):76-83.

15. Sondi I, Salopek-Sondi B. Silver nanoparticles as antimicrobial agent: a case study on E. coli as a model for Gram-negative bacteria. J Colloid Interface Sci. 2004;275(1):177-182.

16. Lara HH, Ayala-Núñez NV, Ixtepan Turrent Ld, Rodríguez Padilla C. Bactericidal effect of silver nanoparticles against multidrug-resistant bacteria. World J Microbiol Biotechnol. 2010;26(4):615-621.

17. Maneerung T, Tokura S, Rujiravanit R. Impregnation of silver nanoparticles into bacterial cellulose for antimicrobial wound dressing. Carbohydr Polym. 2008;72(1):43-51.

18. Knetsch MLW, Koole LH. New strategies in the development of antimicrobial coatings: the example of increasing usage of silver and silver nanoparticles. Polymers. 2011;3(1):340-366.

19. Asharani PV, Low Kah Mun G, Hande MP, Valiyaveettil S. Cytotoxicity and genotoxicity of silver nanoparticles in human cells. ACS Nano. 2009;3(2):279-290.

20. Rodríguez-González B, Burrows A, Watanabe M, Kiely CJ, Liz Marzán LM. Multishell bimetallic AuAg nanoparticles: synthesis, structure and optical properties. J Mater Chem. 2005;15(17):1755-1759.

21. Liu M, Guyot-Sionnest P. Synthesis and Optical Characterization of Au/Ag Core/Shell Nanorods, J Phys Chem. B 2004(108);19: $5882-5888$.

22. Jana NR. Silver coated gold nanoparticles as new surface enhanced Raman substrate at low analyte concentration. Analyst. 2003;128(7): 954-956.

23. Becker J, Zins I, Jakab A, Khalavka Y, Schubert O, Sönnichsen C. Plasmonic focusing reduces ensemble linewidth of silver-coated gold nanorods. Nano Lett. 2008;8(6):1719-1723.

24. Park K, Vaia RA. Synthesis of complex Au/Ag nanorods by controlled overgrowth. Adv Mater. 2008;20(20):3882-3886.

25. Nikoobakht B, El-Sayed MA. Preparation and growth mechanism of gold nanorods (NRs) using seed-mediated growth method. Chem Mater. 2003;15(10):1957-1962.

26. Nima ZA, Mahmood M, Xu Y, et al. Circulating tumor cell identification by functionalized silver-gold nanorods with multicolor, super-enhanced SERS and photothermal resonances. Sci Rep. 2014;4:4752. 
27. Nikoobakht B, Wang J, El-Sayed MA. Surface-enhanced Raman scattering of molecules adsorbed on gold nanorods: off-surface plasmon resonance condition. Chem Phys Lett. 2002;366(1-2):17-23.

28. Huang X, El-Sayed IH, Qian W, El-Sayed MA. Cancer cell imaging and photothermal therapy in the near-infrared region by using gold nanorods. J Am Chem Soc. 2006;128(6):2115-2120.

29. Dickerson EB, Dreaden EC, Huang X, et al. Gold nanorod assisted near-infrared plasmonic photothermal therapy (PPTT) of squamous cell carcinoma in mice. Cancer Lett. 2008;269(1):57-66.

30. Li Z, Huang P, Zhang X, et al. RGD-conjugated dendrimer-modified gold nanorods for in vivo tumor targeting and photothermal therapy. Mol Pharm. 2010;7(1):94-104.

31. Jang B, Park JY, Tung CH, Kim IH, Choi Y. Gold nanorod-photosensitizer complex for near-infrared fluorescence imaging and photodynamic/ photothermal therapy in vivo. ACS Nano. 2011;5(2):1086-1094.

32. Zhang J, Wang M, Webster TJ. Growth process and anticancer properties of gold nanorods. J Biomed Mater Res A. 2017;105(9):2616-2621.
33. van de Broek B, Devoogdt N, D’Hollander A, et al. Specific cell targeting with nanobody conjugated branched gold nanoparticles for photothermal therapy. ACS Nano. 2011;5(6):4319-4328.

34. Baffou G, Quidant R, Girard C. Heat generation in plasmonic nanostructures: influence of morphology. Appl Phys Lett. 2009; 94(15):153109.

35. Hasan W, Stender CL, Lee MH, Nehl CL, Lee J. Tailoring the structure of nanopyramids for optimal heat generation. Nano Lett. 2009;9(4): 1555-1558.

36. Morones JR, Elechiguerra JL, Camacho A, et al. The bactericidal effect of silver nanoparticles. Nanotechnology. 2005;16(10):2346-2353.

37. Song H. Fabrication of silver nanoparticles and their antimicrobial mechanisms. Eur Cells Mater. 2006;11(Suppl 1):58.

38. Gong P. Preparation and antibacterial activity of Fe3O4@ Ag nanoparticles. Nanotechnology. 2007;18(28):285604.
International Journal of Nanomedicine

\section{Publish your work in this journal}

The International Journal of Nanomedicine is an international, peerreviewed journal focusing on the application of nanotechnology in diagnostics, therapeutics, and drug delivery systems throughout the biomedical field. This journal is indexed on PubMed Central, MedLine, CAS, SciSearch $®$, Current Contents $\AA /$ Clinical Medicine,

\section{Dovepress}

Journal Citation Reports/Science Edition, EMBase, Scopus and the Elsevier Bibliographic databases. The manuscript management system is completely online and includes a very quick and fair peer-review system, which is all easy to use. Visit http://www.dovepress.com/ testimonials.php to read real quotes from published authors. 